\title{
Dock3 Stimulates Axonal Outgrowth via GSK-3 $\beta$-Mediated Microtubule Assembly
}

\author{
Kazuhiko Namekata, Chikako Harada, Xiaoli Guo, Atsuko Kimura, Daiji Kittaka, Hayaki Watanabe, \\ and Takayuki Harada \\ Visual Research Project, Tokyo Metropolitan Institute of Medical Science, Tokyo 156-8506, Japan
}

Dock3, a new member of the guanine nucleotide exchange factors, causes cellular morphological changes by activating the small GTPase Rac1. Overexpression of Dock3 in neural cells promotes axonal outgrowth downstream of brain-derived neurotrophic factor (BDNF) signaling. We previously showed that Dock3 forms a complex with Fyn and WASP (Wiskott-Aldrich syndrome protein) family verprolinhomologous (WAVE) proteins at the plasma membrane, and subsequent Racl activation promotes actin polymerization. Here we show that Dock 3 binds to and inactivates glycogen synthase kinase- $3 \beta$ (GSK-3 $\beta$ ) at the plasma membrane, thereby increasing the nonphosphorylated active form of collapsin response mediator protein-2 (CRMP-2), which promotes axon branching and microtubule assembly. Exogenously applied BDNF induced the phosphorylation of GSK- $3 \beta$ and dephosphorylation of CRMP-2 in hippocampal neurons. Moreover, increased phosphorylation of GSK-3 $\beta$ was detected in the regenerating axons of transgenic mice overexpressing Dock 3 after optic nerve injury. These results suggest that Dock3 plays important roles downstream of BDNF signaling in the CNS, where it regulates cell polarity and promotes axonal outgrowth by stimulating dual pathways: actin polymerization and microtubule assembly.

\section{Introduction}

The Rho-GTPases, including Rac1, Cdc42, and RhoA, are best known for their roles in regulating the actin cytoskeleton and are implicated in a broad spectrum of biological functions, such as cell motility and invasion, cell growth, cell polarity, and axonal guidance (Schmidt and Hall, 2002). Activation signals from Rac1 and Cdc42 are relayed to the actin-nucleating complex Arp2/3 by a family of proteins that includes Wiskott-Aldrich syndrome protein (WASP) and WASP family verprolin-homologous protein (WAVE) (Takenawa and Suetsugu, 2007).

Rho-GTPase activation is mediated by guanine nucleotide exchange factors (GEFs), which share two common motifs, the double (Dbl)-homology (DH) domain and the pleckstrin homology (PH) domain (Cerione and Zheng, 1996; Lemmon and Ferguson, 2000). Dock1 (Dock180)-related proteins are a new family of Rho-GEFs that lack the DH/PH domains. Instead, Dock family proteins are characterized by two evolutionarily conserved protein domains termed Dock homology regions 1 and 2 (DHR-1 and DHR-2) (Meller et al., 2005; Côté and Vuori, 2007).

\footnotetext{
Received Sept. 26, 2011; accepted 0ct. 28, 2011.

Author contributions: K.N. and T.H. designed research; K.N., C.H., X.G., A.K., D.K., and H.W. performed research; K.N., C.H., X.G., A.K., H.W., and T.H. analyzed data; K.N. and T.H. wrote the paper.

This study was supported by the Ministry of Education, Culture, Sports, Science and Technology of Japan (K.N., C.H., X.G., A.K.); Takeda Science Foundation (K.N.); the Ministry of Health, Labour and Welfare of Japan; and the Funding Program for Next Generation World-Leading Researchers (NEXT Program) (T.H.). We are grateful to Dr. K. Kaibuchi (Nagoya University) for providing plasmids and antibodies and to Dr. L. F. Parada (University of Texas Southwestern Medical Center) for providing TrkB knock-out mice.

The authors declare no competing financial interests.

Correspondence should be addressed to Dr. Takayuki Harada, Visual Research Project, Tokyo Metropolitan Institute of Medical Science, 2-1-6 Kamikitazawa, Setagaya-ku, Tokyo 156-8506, Japan. E-mail: harada-tk@igakuken.or.jp.

DOI:10.1523/JNEUROSCI.4884-11.2012

Copyright $\odot 2012$ the authors $\quad 0270-6474 / 12 / 320264-11 \$ 15.00 / 0$
}

We recently detected a common active center of Dock $1 \sim 4$ within the DHR-2 domain and reported that the DHR-1 domain is necessary for the direct binding between Dock1 $\sim 4$ and WAVE1 3 (Namekata et al., 2010). We also found that overexpression of Dock3 induced axonal regeneration after optic nerve injury in vivo. We determined a mechanism underlying Dock3-induced axonal outgrowth, in which Dock3 activates Racl and stimulates spatially restricted actin dynamics through formation of a protein complex with Fyn and WAVE downstream of brain-derived neurotrophic factor (BDNF) signaling.

Recent studies have shown that assembly of actin filaments in the growth cone is not a formal requirement for axonal growth. Instead, microtubules have been attracting attention for their key roles in axon structure and organelle transport (Conde and Cáceres, 2009). For example, microtubule assembly promoted by collapsin response mediator proteins (CRMPs) that bind to tubulin heterodimers leads to effective axonal formation (Inagaki et al., 2001). In neurons, CRMPs are expressed in the lamellipodia and filopodia of growth cones, in the shafts of axons, and in cell bodies (Yoshimura et al., 2005). The importance of CRMPs in axonal formation is highlighted by the evidence that axonal outgrowth is arrested when CRMPs are phosphorylated by some kinases, such as glycogen synthase kinase- $3 \beta$ (GSK-3 $\beta$ ), because this phosphorylation causes dissociation of CRMPs from microtubules (Eickholt et al., 2002; Yoshimura et al., 2005). In addition, adenomatous polyposis coli (APC), which promotes microtubule assembly at the growth cone, is another downstream target of GSK-3 $\beta$ (Zhou et al., 2004; Koester et al., 2007; Purro et al., 2008), indicating the importance of GSK-3 $\beta$ in this dynamic process. In this study, we show that Dock 3 binds to GSK-3 $\beta$ and inhibits its activity, thereby activating CRMP-2 and APC. Our results suggest that Dock3 stimulates both actin rearrangement 
A
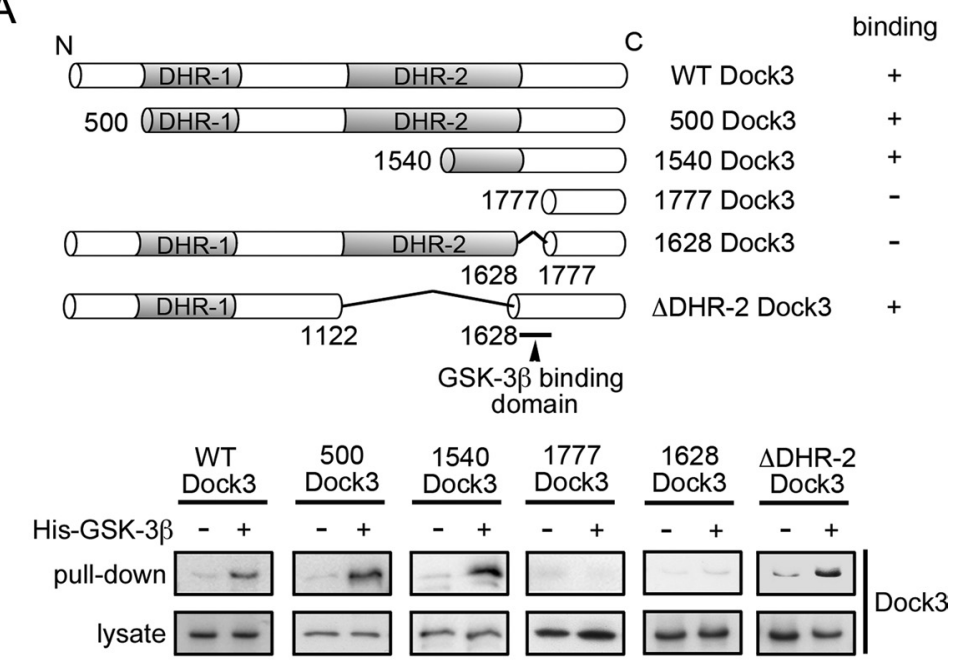

B

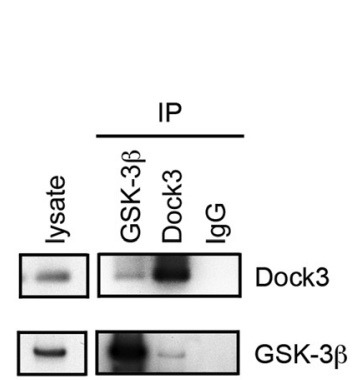

C
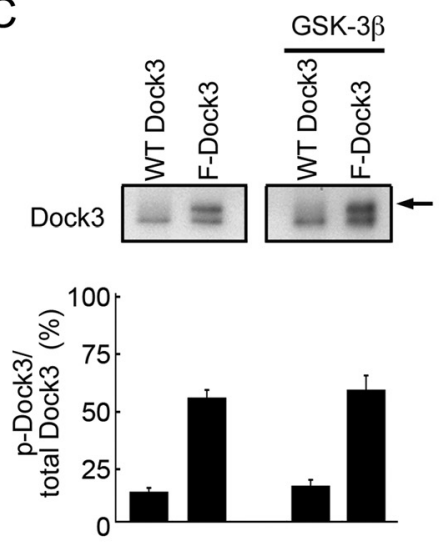

D

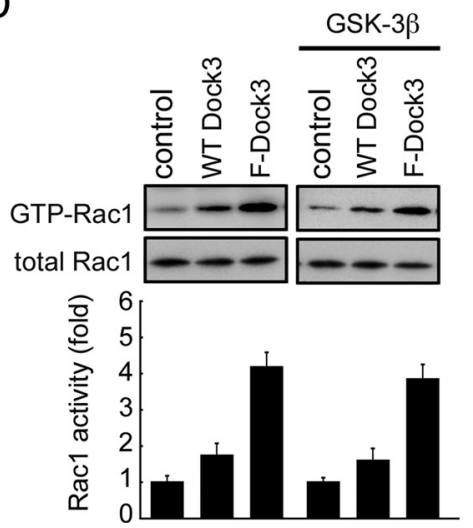

Figure 1. Dock3 interacts with GSK-3 $\beta . A$, Schematic representation showing the WT and mutant Dock 3 constructs used in the pull-down assay (top). Lysates from Cos-7 cells transfected with indicated Dock3 deletion mutants were subjected to a His-tag pull-down assay with an antibody against Dock3 (bottom). B, Coimmunoprecipitation (IP) of Dock3 and GSK-3 $\beta$ in mouse brain lysate. C, Immunoblot analysis of Dock3 in lysates from Cos-7 cells transfected with indicated plasmids. Arrows indicate phosphorylated Dock3. Phosphorylated Dock3 levels were quantified and shown in the histogram. D, Lysates from Cos-7 cells transfected with the indicated plasmids were subjected to a GST-CRIB assay and Rac1 activity was quantified and shown in the histogram.

iments were performed using $\mathrm{TrkB}^{\text {flox/flox }}$ mice $\times$ GFAP-Cre mice (TrkB ${ }^{\text {GFAP }}$ KO mice) or $c$-kit-Cre mice (TrkB ${ }^{\text {c-kit }} \mathrm{KO}$ mice) (Harada et al., 2011) and Dock3 transgenic mice (Namekata et al., 2010). TrkB deletion in the hippocampus and retinal ganglion cells have been confirmed in TrkB GFAP $\mathrm{KO}$ (Luikart et al., 2005) and TrkB ${ }^{\text {c-kit }}$ KO mice (Harada et al., 2011), respectively. C57BL/6J mice were obtained from CLEA Japan.

Expression plasmids. Farnesylation-signalattached Dock3 (F-Dock3) was generated as described previously (Namekata et al., 2004). WT Dock3, mutants of Dock3, WT GSK-3 $\beta$, farnesylation-signal-attachedGSK-3 $\beta$ (F-GSK$3 \beta)$ and Cyclin-dependent kinase $5(\mathrm{Cdk} 5)$ were generated by PCR and subcloned into the pCMV expression vector. Plasmids encoding WT CRMP-2 and CRMP-2 T514D tagged with myc were generous gifts from Dr. K. Kaibuchi (Nagoya University, Aichi, Japan) (Yoshimura et al., 2005). Adenomatous polyposis coli (APC)-targeting siRNA was purchased from Santa Cruz Biotechnology. RNA oligomers containing 21 nucleotides for RNA interference for Dock1 4 were synthesized in the sense and antisense directions (Dock1:5'-GGAAGUCACC ACAACGCUUUU-3'; Dock2: 5'-GCAUCUCA CGCUACAGAUUUU-3'; Dock3: 5'-GCAGAU CAGUGAACGGUUUU-3'; Dock4: 5'-GCAAG AGUGUGGCCAGAAAUU-3') (Namekata et al., 2010). The negative control siRNA was purchased from Invitrogen.

Cell culture and transfection. Transient transfection was performed using Lipofectamine Plus for Cos-7 cells and HEK293T cells (Invitrogen) according to the manufacturer's instructions. In some experiments, cells were treated with BEZ235 (Selleck Chemicals) to inhibit phosphoinositide 3-kinase (PI3K)/Akt signaling. His-tagged GSK-3 $\beta$ was cotransfected with WT Dock3 or deletion mutants of Dock3. CRMP-2 was cotransfected with F-Dock3 and His-tagged GSK- $3 \beta$. Primary cultured hippocampal neurons were prepared as previously reported (Namekata et al., 2010) and stimulated with or without BDNF $(50 \mathrm{ng} / \mathrm{ml})$. Transfection of plasmids and siRNA into primary cultured hippocampal neurons was performed using the Nucleofector System (Amaxa Biosystems). Retinal explant culture was prepared as previously described (Namekata et al., 2010).

Immunoblotting, pull-down assay, and immunoprecipitation. After $24 \mathrm{~h}$ of transfection, the cell lysate was incubated with TALON resin (BD Biosciences) for $20 \mathrm{~min}$ at $4^{\circ} \mathrm{C}$ with gentle agitation. After being washed, precipitated samples were subjected to SDS-PAGE followed by immunoblot analysis as previously described (Namekata et al., 2008).

and microtubule assembly pathways, which are critical for axonal outgrowth.

\section{Materials and Methods}

Animals. All procedures involving animals were approved by the Institutional Animal Care and Use Committees of the Tokyo Metropolitan Institute of Medical Science in accordance with the Standards Relating to the Care and Management of Experimental Animals in Japan. Exper-
Membrane fractionation was performed as previously described ( $\mathrm{Na}-$ kamura et al., 2007). The following antibodies were used: anti-Dock3 antibody (Namekata et al., 2010), anti-myc antibody (Santa Cruz Biotechnology), anti-Racl antibody (BD Biosciences), anti-APC antibody (Cell Signaling Technology), anti-phosphorylated-serine antibody (Rockland), antiGSK-3 $\beta$ antibody (BD Biosciences), anti-phosphorylated-GSK-3 $\beta$ (Ser9) antibody (BD Biosciences), anti-CRMP-2 antibody (MBL, Nagoya, Japan), anti-pT514-CRMP-2 antibody (Yoshimura et al., 2005), and 
anti-pS522-CRMP-2 antibody (ECM Bioscience). Immunoprecipitation was performed as previously described (Nakamura et al., 2007).

Measurement of Rac1 and GSK-3 $\beta$ activities. Racl activity was measured as described previously (Namekata et al., 2004). Briefly, glutathione S-transferase (GST)-fused CRIB (Cdc42/ Rac interactive binding motif)-bound Racl was purified from the bacterial lysate using glutathione-agarose (GE Healthcare). After $24 \mathrm{~h}$ of transfection, Cos-7 cells were washed twice with PBS, lysed in the lysis buffer (1\% Triton X-100, 50 mm Tris, pH 7.4, $150 \mathrm{~mm} \mathrm{NaCl,} \mathrm{10 \%}$ glycerol and $10 \mathrm{~mm} \mathrm{MgCl}_{2}$ containing protease inhibitor mixture), and centrifuged for $15 \mathrm{~min}$ at $10,000 \times g$ at $4^{\circ} \mathrm{C}$. Racl bound to GST-CRIB was resolved by SDS-PAGE and assessed by immunoblot analysis. GSK-3 $\beta$ activity was measured using an immune complex in vitro kinase assay (Huang and Guo, 2006). Hippocampal neurons were treated with BDNF $(100 \mathrm{ng} / \mathrm{ml})$ for $5 \mathrm{~min}$ and GSK- $3 \beta$ was immunoprecipitated using an anti-GSK- $3 \beta$ antibody. Kinase activity of immunoprecipitated GSK- $3 \beta$ was assayed using GSTtau as a substrate in an assay buffer $(40 \mathrm{~mm}$ HEPES, pH 7.2, 5 mM $\mathrm{MgCl}_{2}, 5$ mM EDTA, 200 $\mu \mathrm{M}$ ATP, $50 \mu \mathrm{g} / \mathrm{ml}$ heparin). The mixture was incubated at $30^{\circ} \mathrm{C}$ for $1 \mathrm{~h}$. Phosphorylation of tau at Ser396 was determined by immunoblot analysis using an anti-tau (pS396) antibody (Invitrogen).

Immunostaining. HEK293T cells were fixed and incubated with an anti-Dock 3 antibody, anti-GSK- $3 \beta$ antibody, anti-phosphorylatedGSK-3 $\beta$ antibody, and anti-pan-cadherin antibody (Abcam). Cultured hippocampal neurons were incubated with antibodies against total CRMP-2 and pT514-CRMP-2. Retinal explants were stained with antibodies against Dock3 and GSK-3 $\beta$ or phosphorylated-GSK-3 $\beta$. Samples were viewed by epifluorescence on a light microscope (BX51; Olympus) equipped with Plan Fluor objectives and connected to a DP70 camera (Olympus).

Optic nerve injury. Mice were anesthetized with sodium pentobarbital before optic nerve crushing. Optic nerves were exposed intraorbitally and crushed at $\sim 0.5-1.0 \mathrm{~mm}$ from the posterior pole of the eyeball with fine surgical forceps for $5 \mathrm{~s}$ (Fischer et al., 2004; Namekata et al., 2010). Fourteen days after surgery, protein expression levels in the lesion site were measured by immunoblot analysis with antibodies against total-GSK- $3 \beta$, phosphorylated-GSK-3 $\beta$ and actin. Regenerating axons were double-stained with antibodies against GAP43 (Millipore Bioscience Research Reagents) and phosphorylated-GSK-3 $\beta$.

Image analysis and statistics. Hippocampal neurons were fixed at $3 \mathrm{~d}$ in vitro, stained with an anti-tau antibody, and the number of axonal branching and the rate of neurons with multiple neurites were examined. To measure axon length, the longest axon of each neuron was traced and calculated using National Institutes of Health ImageJ software (version 1.38). Approximately 50 neurons with axons were scanned using a DP70 CCD camera (Olympus). The intensity of intracellular fluorescence was analyzed using the same software as above. Data are presented as means \pm SEs unless noted otherwise. Statistical analyses were performed using two-tailed Student's $t$ test or ANOVA with Dunnett's post hoc tests. Results were considered statistically significant if $p<0.05$.
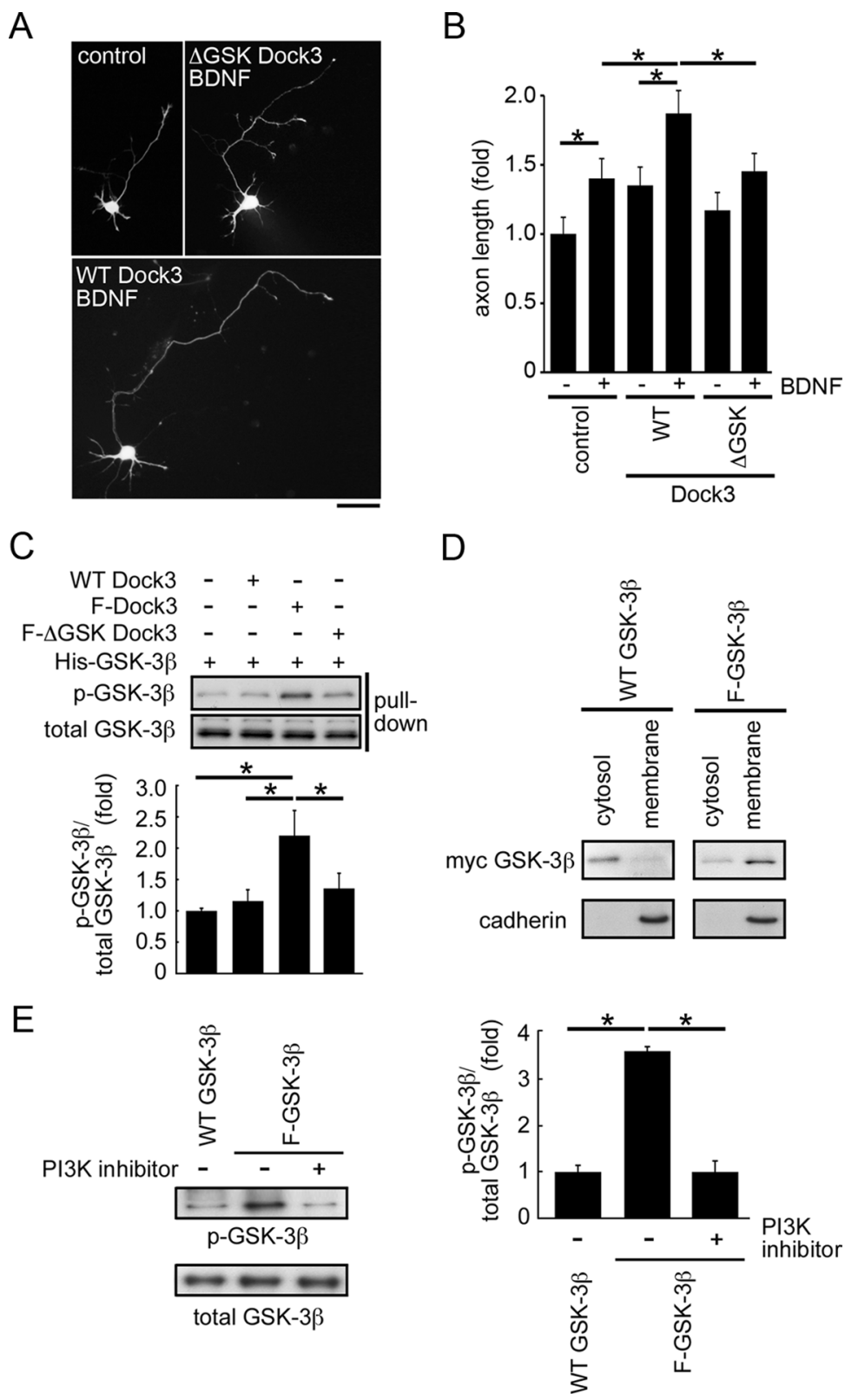

Figure 2. Dock3-induced phosphorylation of GSK-3 $\beta$ is required for BDNF-mediated axonal outgrowth. $A$, Hippocampal neurons transfected with WT Dock3 and Dock3 mutants were cultured in the presence or absence of BDNF for $3 \mathrm{~d}$. Scale bar, $20 \mu \mathrm{m} . \boldsymbol{B}$, Hippocampal neurons transfected and treated as shown on the $x$-axis were fixed at $3 \mathrm{~d}$ in vitro, and axon length was measured. $n=$ 30 per experimental condition. C, Lysates from Cos-7 cells transfected as indicated above the immunoblot images were subjected to a His-tag pull-down assay with antibodies against total and phosphorylated GSK-3 $\beta$. Phosphorylated GSK-3 $\beta$ (Ser9) levels were quantified and shown in the histogram. $\boldsymbol{D}$, Cytosolic and membrane fractions were prepared from Cos-7 cells transfected with myc-tagged WT GSK-3 $\beta$ or F-GSK-3 $\beta$ and subjected to immunoblot analyses with antibodies against myc-tag (total GSK- $3 \beta$ ) and cadherin. $\boldsymbol{E}$, Lysates from Cos-7 cells transfected with WT GSK-3 $\beta$ or F-GSK-3 $\beta$ with or without PI3K inhibitor were subjected to immunoblot analyses with antibodies against total and phosphorylated GSK-3 $\beta$. Phosphorylated GSK-3 $\beta$ levels were quantified and shown in the histogram. Data are presented as means \pm SEs for each group from three independent experiments. ${ }^{*} p<0.05$.

\section{Results}

\section{Interaction of Dock 3 and GSK-3 $\beta$ stimulates} axonal outgrowth

We first examined whether Dock3 binds to GSK-3 $\beta$ using a Histag pull-down assay. For this experiment, we used Cos-7 cells transfected with His-tagged wild-type Dock3, i.e., WT Dock3 or truncated mutants lacking the region of amino acids encompassing residues 1-500 (500 Dock3), 1-1540 (1540 Dock3), 1-1777 (1777 Dock3), 1628-1777 (1628 Dock3), or the Rac1 binding site 
A
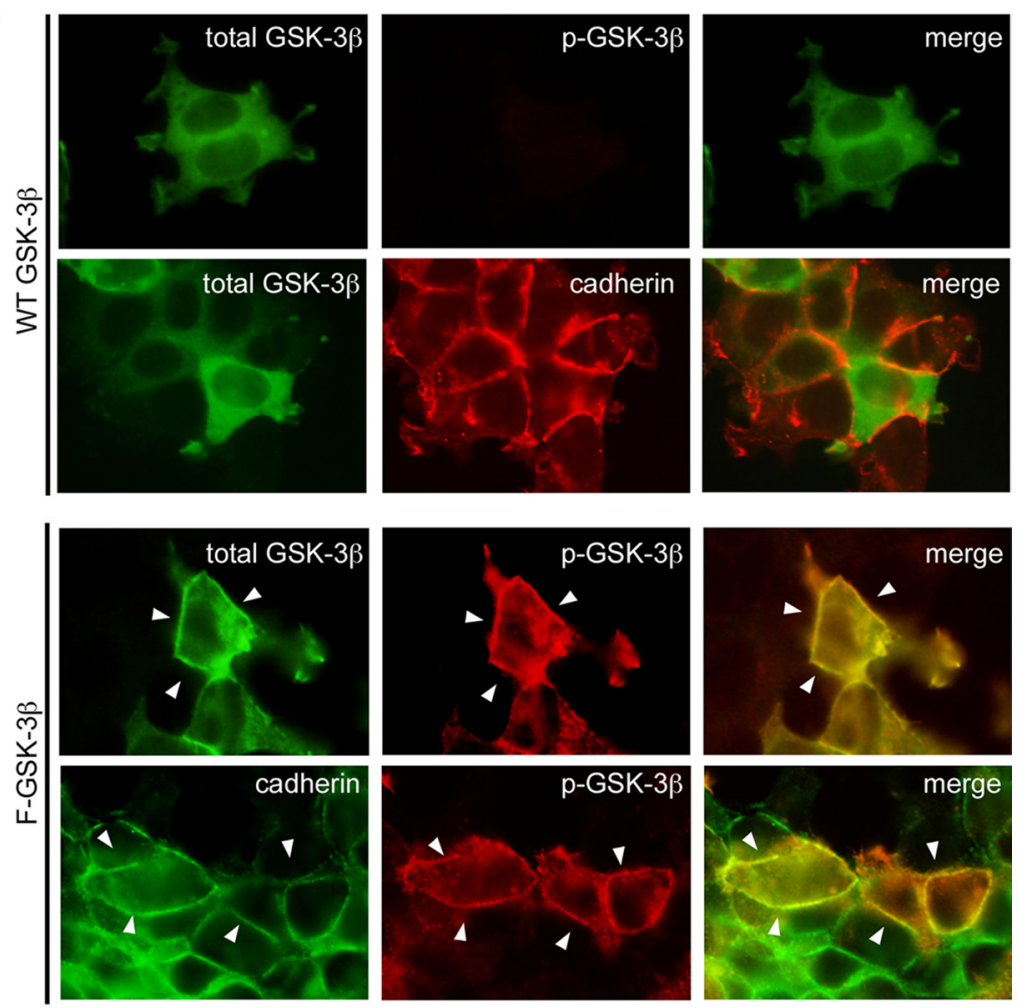

B
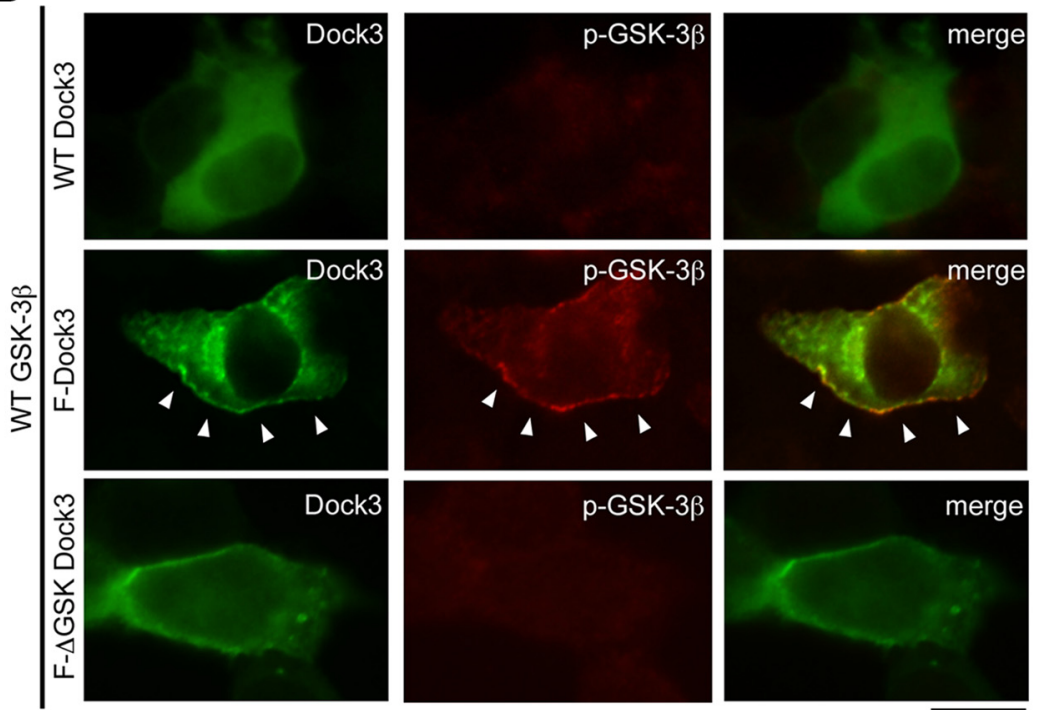

Figure 3. Dock3 promotes membrane recruitment and phosphorylation of GSK-3 $\beta$. A, HEK293T cells transfected with WT GSK-3 $\beta$ or F-GSK- $3 \beta$ were double-labeled with antibodies against total GSK- $3 \beta$ (green) and phosphorylated GSK- $3 \beta$ ( $p$-GSK-3 $\beta$; red) or cadherin (red). Arrowheads indicate p-GSK-3 $\beta$ localized to the plasma membrane. Scale bar, $10 \mu \mathrm{m}$. B, HEK293T cells cotransfected with WT GSK-3 $\beta$ and myc-tagged Dock3 mutants were double-labeled with antibodies against myc-tag (F-Dock3; green) and p-GSK-3 $\beta$ (red). Arrowheads indicate p-GSK-3 $\beta$ localized to the plasma membrane. Scale bar, $10 \mu \mathrm{m}$.

( $\triangle$ DHR-2 Dock3) (Fig. $1 A$ ). We found that GSK-3 $\beta$ binds to WT Dock3, 500 Dock3, 1540 Dock3 and $\Delta$ DHR-2 Dock3, while 1777 Dock 3 and 1628 Dock 3 failed to bind to GSK-3 $\beta$ (Fig. $1 A$ ). These results revealed that GSK-3 $\beta$ binds to Dock3 and that the binding domain is located between amino acids $1628-1777$ of the Dock3 protein. For convenience, 1628 Dock3 is referred to as " $\Delta$ GSK Dock3" thereafter. The interaction of endogenous Dock3 and GSK- $3 \beta$ was also confirmed in mouse brain lysate by a coimmunoprecipitation assay (Fig. $1 B$ ). We previously reported that phosphorylation of Dock3 at the plasma membrane regulates its interaction with WAVE (Namekata et al., 2010). Because phosphorylated Dock3 was detected as an upper mobility band in SDS-PAGE in the previous study, immunoblot analysis was applied again to determine the phosphorylation state. To assess whether GSK-3 $\beta$ phosphorylates Dock3, lysates from Cos-7 cells transfected with GSK-3 $\beta$ and FDock3, which contains a farnesylation signal sequence for plasma membrane localization, were subjected to immunoblot analysis. However, GSK-3 $\beta$ failed to increase F-Dock3 phosphorylation (Fig. $1 C)$. We next examined endogenous Racl activity in these cells. Racl activity was increased by Dock3, but GSK-3 $\beta$ showed no additional effect (Fig. 1D).

GSK- $3 \beta$ has important roles in axonal initiation and elongation in neurons (Zhou and Snider, 2005; Hur and Zhou, 2010). To evaluate whether the interaction between Dock3 and GSK-3 $\beta$ affects axonal outgrowth, we transfected primary cultured hippocampal neurons with a plasmid encoding WT Dock3 or $\Delta$ GSK Dock 3 and treated them with or without BDNF. As previously reported, overexpression of WT Dock3 significantly increased axonal length, but $\triangle$ GSK Dock3 had no synergistic effects (Fig. 2A,B). These results suggest that the interaction of Dock 3 and GSK- $3 \beta$ promotes BDNFdependent axonal outgrowth without affecting the phosphorylation state or GEF activity of Dock3.

\section{Dock3 induces phosphorylation of GSK-3 $\beta$ at the plasma membrane}

We next examined the possibility that Dock 3 affects GSK-3 $\beta$ activity by changing its phosphorylation state. We cotransfected Cos-7 cells with His-tagged GSK- $3 \beta$ and WT Dock 3 or F-Dock 3 and purified GSK-3 $\beta$ by a His-tagged pulldown assay. Precipitants were subjected to immunoblot analyses with an antibody against phosphorylated GSK-3 $\beta$ (Ser9); phosphorylation at this site inhibits its kinase activity (Beaulieu et al., 2009). Immunoblot analyses revealed that F-Dock3, but not WT Dock3, increased GSK-3 $\beta$ phosphorylation at Ser9 (Fig. 2C). In addition, F- $\Delta$ GSK Dock3, in which a farnesylation signal sequence for enforcing plasma membrane localization is attached to $\Delta \mathrm{GSK}$ Dock3, failed to stimulate GSK-3 $\beta$ phosphorylation (Fig. $2 C$ ). These results led us to speculate that the interaction between Dock 3 and GSK- $3 \beta$ at the plasma membrane promotes the phosphorylation (i.e., inactivation) of GSK-3 $\beta$. To further explore the possibility of this interaction, we prepared F-GSK- $3 \beta$, in which a farnesylation signal sequence is attached to WT GSK- $3 \beta$. When transfected with Cos-7 cells, F-GSK-3 $\beta$ was concentrated in the 
membrane fraction, whereas WT-GSK-3 $\beta$ was mainly detected in the cytosolic fraction (Fig. 2D). We next examined whether the GSK-3 $\beta$ phosphorylation level is increased at the plasma membrane. As predicted, the phosphorylation rate of F-GSK- $3 \beta$ was much greater than that of WT GSK-3 $\beta$ (Fig. $2 E)$. In addition, the phosphorylation of F-GSK- $3 \beta$ was suppressed by a PI3K inhibitor, indicating that PI3K/Akt signaling is involved in GSK-3 $\beta$ phosphorylation at the plasma membrane (Fig. 2E).

We further examined the localization of total and phosphorylated GSK-3 $\beta$ in HEK293T cells transfected with WT GSK- $3 \beta$ or F-GSK- $3 \beta$. Immunocytochemical analyses revealed that F-GSK-3 $\beta$, but not WT GSK-3 $\beta$, was phosphorylated, and such phosphorylated F-GSK-3 $\beta$ was colocalized with cadherin, indicating that GSK-3 $\beta$ phosphorylation occurs exclusively at the plasma membrane (Fig. 3A, arrowheads). We also found that F-Dock3 recruits GSK- $3 \beta$ to the plasma membrane and induces its phosphorylation (Fig. $3 B$ ). In contrast, WT Dock 3 and F- $\Delta$ GSK Dock 3 failed to induce the phosphorylation of GSK-3 $\beta$. These results suggest that membrane recruitment of the Dock3-GSK-3 $\beta$ complex stimulates GSK-3 $\beta$ phosphorylation, which may lead to axonal outgrowth via microtubule assembly (Eickholt et al., 2002; Yoshimura et al., 2005).

BDNF-Dock3 pathway regulates GSK$3 \boldsymbol{\beta}$-dependent microtubule assembly BDNF-TrkB receptor signaling stimulates membrane recruitment of Dock3 and induces axonal outgrowth by stimulating actin reorganization (Namekata et al., 2010). Because Dock3 may also enhance axonal outgrowth by stimulating microtubule assembly via regulation of GSK- $3 \beta$ activity, we examined the effect of BDNF on the phosphorylation state of GSK-3 $\beta$. BDNF stimulated GSK- $3 \beta$ phosphorylation in hippocampal neurons from WT but not from TrkB ${ }^{\text {GFAP }}$ KO mice (Fig. $4 A$ ). GSK-3 $\beta$ phosphorylation at Ser9 prevents subsequent phosphorylation of CRMP-2 at Thr514, which induces axon elongation via stimulation of microtubule assembly (Yoshimura et al., 2005). BDNF consistently suppressed CRMP-2 phosphorylation (pT514-CRMP-2) in hippocampal neurons from WT but not from TrkB GFAP KO mice (Fig. $4 B$ ).

Because Dock 3 induces GSK-3 $\beta$ phosphorylation at Ser9 (Figs. $2 C, 3 B$ ), we next examined whether Dock3 alters the phosphorylation state of CRMP-2. For this purpose, we transfected Cos-7 cells with WT CRMP-2, WT GSK-3 $\beta$ and F-Dock3 and
A
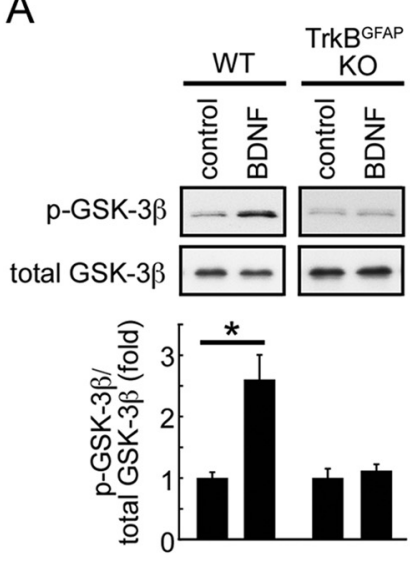

C
B

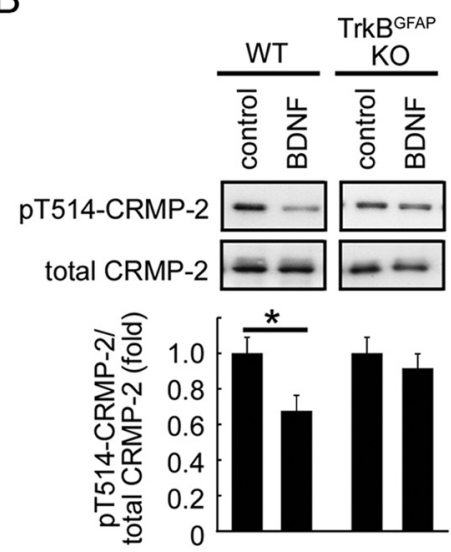

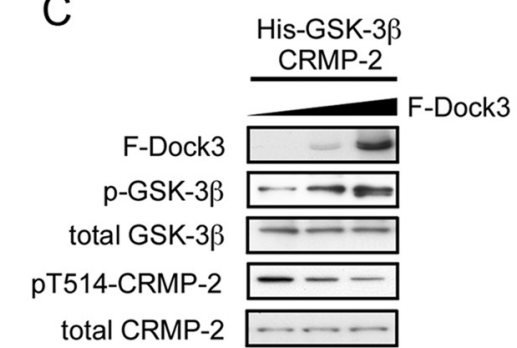
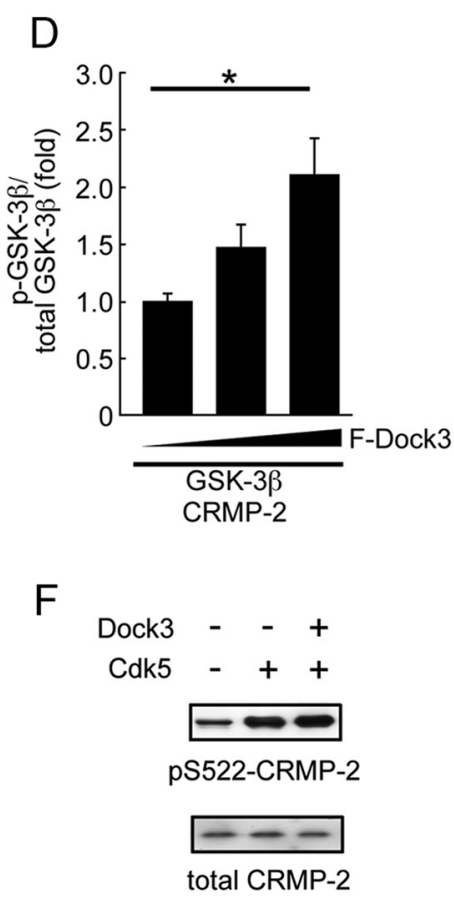

E
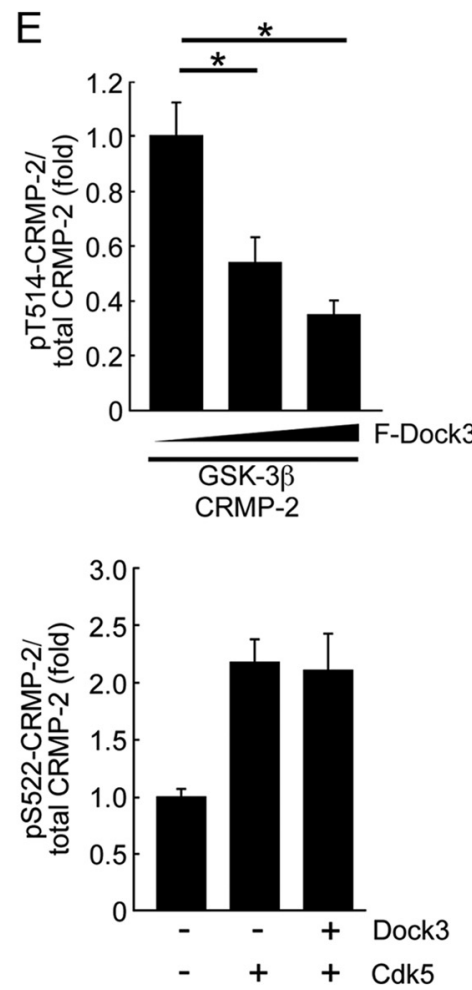

Figure 4. Dock3 suppresses CRMP-2 phosphorylation via GSK-3 $\beta$ phosphorylation. $A, B$, Immunoblot analysis of GSK-3 $\beta$ and CRMP-2 after BDNF stimulation in cultured hippocampal neurons from WT or TrkB GFAP $K 0$ mice. Phosphorylated GSK-3 $\beta$ (p-GSK-3 $\beta$ ) and CRMP-2 (pT514-CRMP-2) were detected using specific antibodies against phosphorylated GSK-3 $\beta$ (ser9) and pT514-CRMP-2, respectively. Expression levels of $p$-GSK-3 $\beta$ and TT514-CRMP- 2 were quantified and shown in the histogram. Data are presented as means \pm SEs for each group from three independent experiments. ${ }^{*} p<0.05$. C, A fixed amount of plasmids encoding His-GSK-3 $\beta$ and CRMP-2 and an increasing amount of the plasmid encoding F-Dock3 were transfected into Cos-7 cells. Lysates from Cos-7 cells were subjected to immunoblot analyses with antibodies against Dock3, p-GSK-3 $\beta$, total GSK-3 $\beta$, pT514-CRMP-2, and total CRMP-2. D, E, Expression levels of p-GSK-3 $\beta$ and pT514-CRMP-2 were quantified and shown in the histogram. Data are presented as means \pm SEs for each group from three independent experiments. ${ }^{*} p<0.05 . \boldsymbol{F}$, Lysates from Cos-7 cells transfected as shown at the top of the images were subjected to immunoblot analyses with antibodies against pS522-CRMP-2 and total CRMP-2. Expression levels of pS522-CRMP-2 and total CRMP-2 were quantified and shown in the histogram. Data are presented as means \pm SEs for each group from three independent experiments. 
A
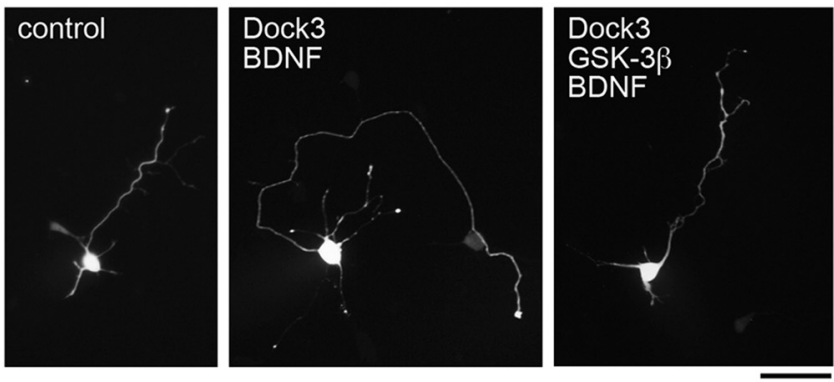

B

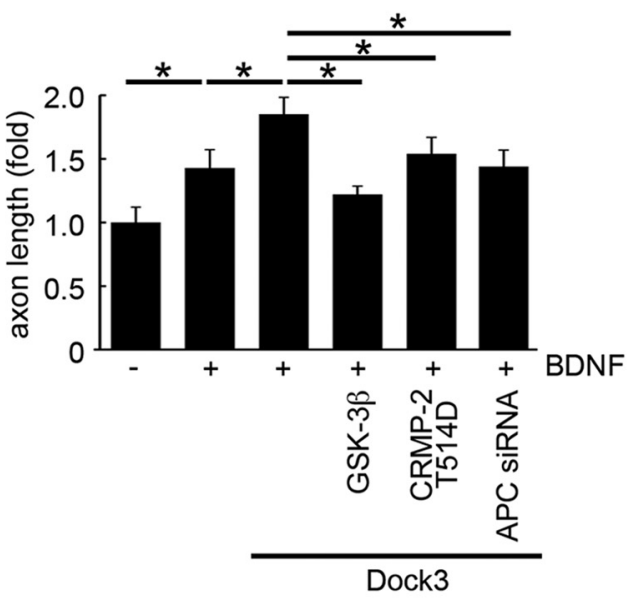

C
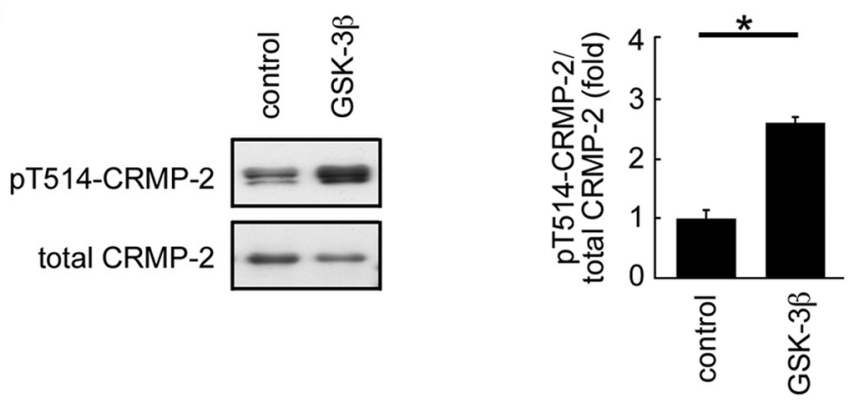

D

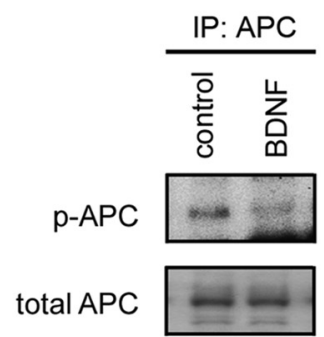

E

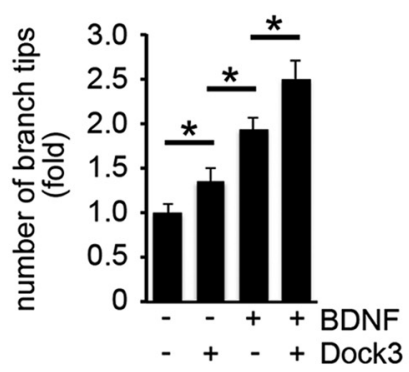

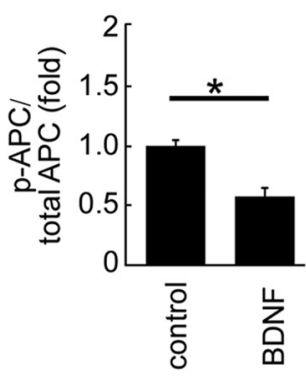

$\mathrm{F}$

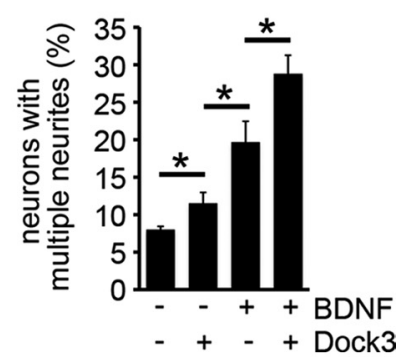

Figure 5. BDNF-Dock3 pathway regulates microtubule assembly-mediated axonal outgrowth and axonal branching. $\boldsymbol{A}$, Hippocampal neurons transfected with WT Dock3 and WT GSK- $3 \beta$ were cultured in the presence or absence of BDNF $(50 \mathrm{ng} / \mathrm{ml})$ for $3 \mathrm{~d}$.

subjected the cell lysates to immunoblot analyses. We found that F-Dock3 induces dephosphorylation of CRMP-2, as well as phosphorylation of GSK- $3 \beta$, in a concentration-dependent manner (Fig. 4C-E). These results suggest that Dock3 activates CRMP-2 indirectly via GSK- $3 \beta$ phosphorylation. CRMP-2 can be phosphorylated by $\mathrm{Cdk} 5$ at Ser522, and by recognizing this priming phosphorylation, GSK- $3 \beta$ phosphorylates CRMP-2 at Thr514 (Cheung et al., 2007). Thus, Cdk5-induced phosphorylation of CRMP-2 at Ser522 (pS522CRMP-2) may be required for the induction of pT514-CRMP-2 by GSK-3 $\beta$. We examined whether Dock3 also influences the Cdk5-mediated induction of pS522-CRMP-2; however, overexpression of Dock3 had no effect on its expression level (Fig. $4 F$ ). These results suggest that Cdk5-mediated induction of pS522CRMP-2 is independent of Dock3-mediated CRMP-2 dephosphorylation by GSK- $3 \beta$ inactivation.

To evaluate the role of GSK- $3 \beta$ and CRMP-2 in BDNF-induced axonal outgrowth, we transfected primary hippocampal neurons with plasmids encoding WT Dock 3 and WT GSK-3 $\beta$ or CRMP-2 T514D, which mimics CRMP-2 phosphorylated at Thr514 by GSK-3 $\beta$ (Yoshimura et al., 2005). We found that overexpression of either WT GSK-3 $\beta$ or CRMP-2 T514D suppressed BDNF-Dock3 pathway-mediated axonal outgrowth (Fig. 5A, $B$ ). In addition, we confirmed that overexpression of GSK-3 $\beta$ increased the expression of pT514CRMP-2 that suppresses microtubule assembly (Fig. 5C). Another downstream

\section{$\leftarrow$}

Scale bar, $20 \mu \mathrm{m}$. B, Hippocampal neurons transfected and treated as shown at the $x$-axis were fixed at $3 \mathrm{~d}$ in vitro, and axon length was measured. $n=30$ per experimental condition. Data are presented as means $\pm S E s$ of three independent experiments. ${ }^{*} p<0.05$. C, Hippocampal neurons transfected with WT GSK-3 $\beta$ were subjected to immunoblot analyses with antibodies against pT514-CRMP-2 and total CRMP-2. Expression levels of pT514-CRMP- 2 and total CRMP-2 were quantified and shown in the histogram. Data are presented as means \pm SEs for each group from three independent experiments. ${ }^{*} p<0.05$. D, Lysates obtained from hippocampal neurons, stimulated with BDNF, were immunoprecipitated with an anti-APC antibody. The immunoprecipitates were probed with anti-phosphorylated serine antibody. Expression levels of phosphorylated APC (p-APC) were quantified and shown in the histogram. Data are presented as means \pm SEs for each group from three independent experiments. ${ }^{*} p<$ 0.05. $\boldsymbol{E}, \boldsymbol{F}$, Hippocampal neurons transfected and treated as shown at the $x$-axis were fixed at $3 \mathrm{~d}$ in vitro, and the number of branching tips per axons and the rate of neurons with multiple neurites were measured. $n=30$ per experimental condition. Data are presented as means \pm SEs of three independent experiments. ${ }^{*} p<0.05$. 
target of GSK-3 $\beta$ is adenomatous polyposis coli (APC), which promotes microtubule assembly at the growth cone when dephosphorylated (Zhou et al., 2004; Koester et al., 2007; Purro et al., 2008). We found that knockdown of APC also suppressed Dock3-mediated axonal outgrowth after BDNF treatment (Fig. 5B), and that BDNF induced APC dephosphorylation, which in turn would promote microtubule assembly (Fig. 5D). Since BDNF is known to influence neuronal cell polarity (Arimura and Kaibuchi, 2007), we examined whether Dock3 is involved in this process in hippocampal neurons. We found that overexpression of Dock3 increases the number of axon branching and neurons with multiple neurites (Fig. 5E,F). These results suggest that, in addition to Racl activation, Dock3dependent GSK-3 $\beta$ phosphorylation (i.e., inactivation) plays a role in the BDNF-mediated axonal outgrowth and cell polarity (Kim et al., 2006; Zhao et al., 2009).

To examine the effect of endogenous Dock GEFs on GSK-3 $\beta$ activity in the growth cone, we performed an RNA interference experiment to knockdown Dock1 $\sim 4$ in hippocampal neurons. We measured GSK- $3 \beta$ activity by quantifying CRMP-2 phosphorylation levels. We found that BDNF induces CRMP-2 dephosphorylation, whereas combinational knockdown of Dock1 4, but not Dock3 alone, suppresses BDNF-induced CRMP-2 dephosphorylation (Fig. 6A,B). The negative control siRNA had no effect on BDNF-induced CRMP-2 dephosphorylation. Our observations demonstrate Dock1 $\sim 4$ are necessary for GSK-3 $\beta$-mediated CRMP-2 dephosphorylation. The lack of effect by Dock3 knockdown alone can be explained by the compensatory mechanisms exerted by Dock1, 2 and 4, as they share a common active center (Namekata et al., 2010). To determine GSK-3 $\beta$ activity more directly in hippocampal neurons, we performed an in vitro kinase assay using GST-tau as a substrate (Huang and Guo, 2006). BDNF reduced the kinase activity of GSK-3 $\beta$, and combinational knockdown of Dock1 4 suppressed this BDNF-induced GSK-3 $\beta$ inactivation (Fig. 6C). Consistently, BDNF-dependent GSK-3 $\beta$ phosphorylation was suppressed by the combinational knockdown of Dock1 $\sim 4$ (Fig. $6 D$ ). The negative control siRNA had no effect on BDNF-induced GSK-3 $\beta$ activation nor phosphorylation.

\section{GSK-3 $\beta$ activity during axonal regeneration in Dock3 transgenic mice}

To examine whether Dock3 also alters GSK-3 $\beta$ activity in vivo, we used transgenic (Tg) mice overexpressing WT Dock3. Increased Dock3 expression has been detected in many tissues, especially in the retina and optic nerve (Namekata et al., 2010). Therefore, we prepared retinal explants from WT and Dock3 Tg mice and examined the intracellular localization of GSK-3 $\beta$ after BDNF stimulation. Compared with WT explants, BDNF treatment resulted in accumulation of GSK-3 $\beta$ at the peripheral region of the growth cone in Dock3 Tg explants (Fig. 7A, arrowheads and arrows), suggesting an enhanced GSK- $3 \beta$ recruitment to the plasma membrane (Fig. $7 B$ ). Double-labeling immunocytochemistry revealed that Dock3 and phosphorylated-GSK-3 $\beta$ (p-GSK-3 $\beta$ ) were colocalized at the plasma membrane after BDNF stimulation (Fig. $7 C, D$, arrowheads). Our observations confirmed that membrane recruitment of the Dock3-GSK-3 $\beta$ complex stimulates GSK-3 $\beta$ phosphorylation in neural growth cones as well as in HEK293T cells (Fig. 3).

Because optic nerve regeneration was enhanced in Dock $3 \mathrm{Tg}$ mice (Namekata et al., 2010), we prepared the optic nerve microcrush model and examined the GSK- $3 \beta$ phosphorylation level in the regenerating axons. Immunoblot analysis revealed that the GSK-3 $\beta$ phosphorylation rate in Dock3 $\mathrm{Tg}$ mice was much greater than that in WT and TrkB ${ }^{\mathrm{c}-k i t} \mathrm{KO}$ mice (Fig. $8 A$ ). Immu-
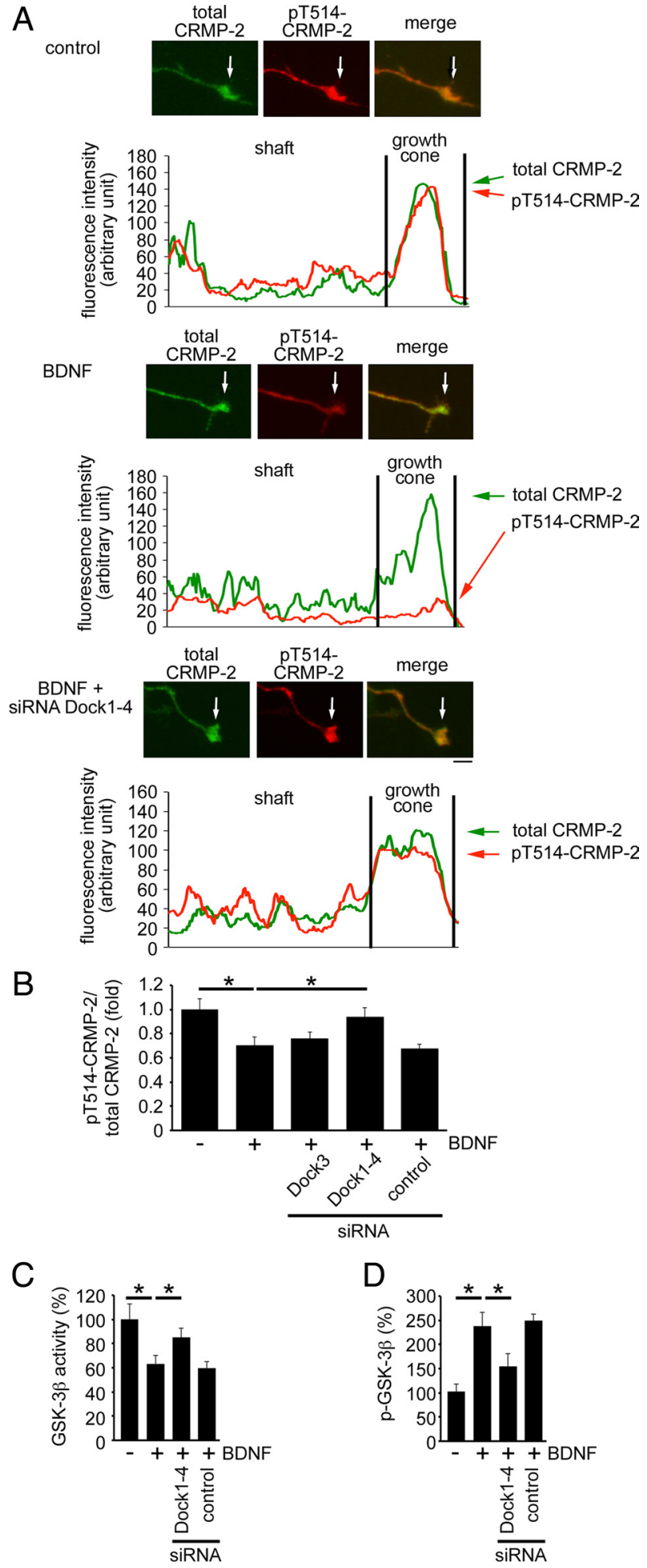

Figure 6. BDNF decreased the phosphorylation levels of CRMP-2 in the axonal growth cones A, Hippocampal neurons treated with $50 \mathrm{ng} / \mathrm{ml} \mathrm{BDNF}$ for 15 min were fixed and immunostained with antibodies against pT514-CRMP-2 and total CRMP-2. The fluorescence intensities were measured in the growth cones and shafts. Scale bar, $5 \mu \mathrm{m}$. $\boldsymbol{B}$, Expression levels of pT514CRMP-2 and total CRMP-2 were quantified and shown in the histogram. $n=20$ per each experimental condition. Data are presented as means \pm SEs. ${ }^{*} p<0.05$. C, D, Hippocampal neurons transfected and treated as shown at the $x$-axis were subjected to in vitro kinase assay using GST-tau as a substrate $(\boldsymbol{C})$ and immunoblot analysis with an antibody against phosphorylated GSK-3 $\beta(\boldsymbol{D})$. Data are presented as means \pm SEs for each group from three independent experiments. ${ }^{*} p<0.05$. 
A
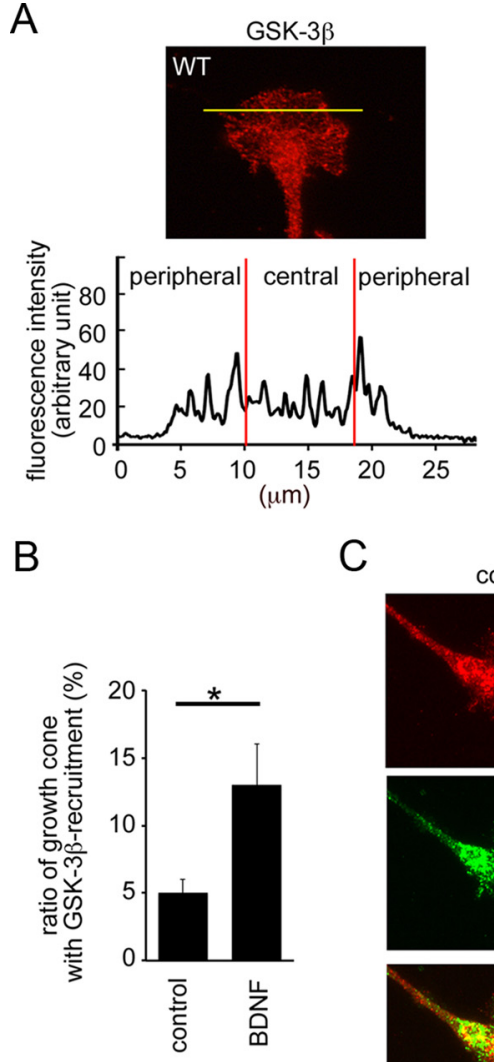

C
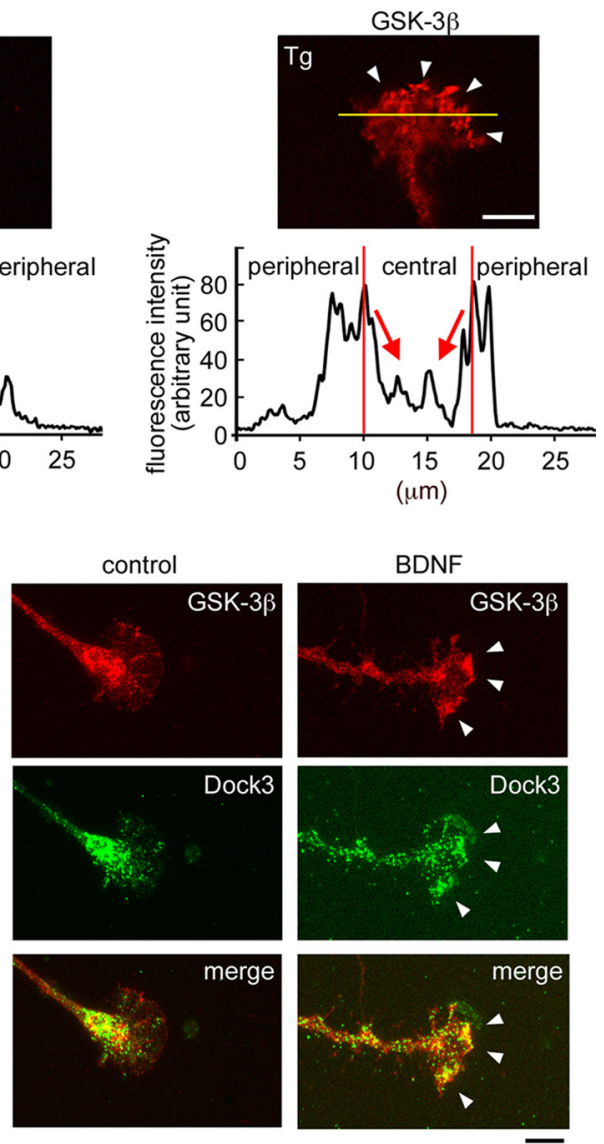

D
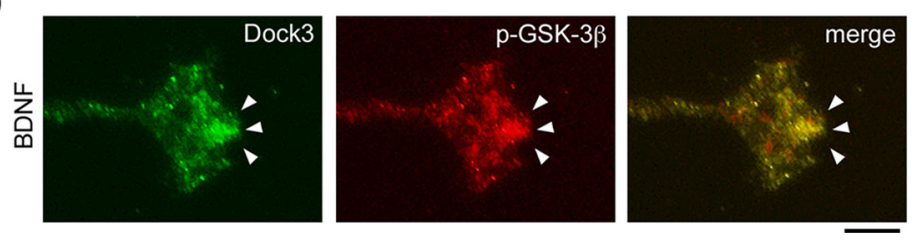

Figure 7. Overexpression of Dock3 induces membrane recruitment and phosphorylation of GSK-3 $\beta$. $A$, Growth cones of retinal explant cultures from WT and Dock3 Tg mice were immunostained with an antibody against GSK-3 $\beta$ after BDNF stimulation. Graphs plot the fluorescence intensity of immunolabeled GSK-3 $\beta$ in the lines shown in each growth cone image. Scale bar, $5 \mu \mathrm{m}$. $\boldsymbol{B}$, Ratio of growth cones in which GSK-3 $\beta$ was recruited to the plasma membrane. $n=20$ for each experimental condition. Data are presented as means \pm SEs for each group from three independent experiments. ${ }^{*} p<0.05$. C, D, Immunostaining of the growth cones of retinal explant cultures from Dock3 Tg mice. Arrowheads indicate colocalization of Dock3 (green) and GSK-3 $\beta$ (red) or phosphorylated GSK-3 $\beta$ (p-GSK-3 $\beta$; red) at the plasma membrane after BDNF treatment. Scale bars, $5 \mu \mathrm{m}$.

nohistochemical analysis of GAP43 and p-GSK- $3 \beta$ in injured optic nerves revealed that their coexpression was increased in regenerating axons of Dock $3 \mathrm{Tg}$ mice (Fig. $8 \mathrm{~B}, \mathrm{C}$ ). These results suggest that Dock3 promotes axonal regeneration by stimulating GSK- $3 \beta$ phosphorylation in the CNS in vivo.

\section{Discussion}

Here we revealed that Dock3 binds to GSK- $3 \beta$ and enhances BDNF-dependent axonal outgrowth by inactivating GSK-3 $\beta$. We demonstrated a BDNF-Dock3-GSK-3 $\beta$ pathway in which Dock3 promoted membrane recruitment of GSK- $3 \beta$ and induced its phosphorylation at the plasma membrane that leads to GSK- $3 \beta$ inactivation. GSK-3 $\beta$ is emerging as a master regulator of microtubule dynamics in growth cones; it phosphorylates several substrates including CRMPs, APC and cytoplasmic linker-associated proteins (CLASPs) (Yoshimura et al., 2005; Kim et al., 2006; Kumar et al., 2009). GSK-3 $\beta$ phosphorylation inhibits binding of
CRMP-2 and APC to tubulin dimmers and thus, promotes microtubule polymerization and induces axonal outgrowth.

We have shown that Dock3 inactivates GSK- $3 \beta$, suggesting Dock 3 plays an important role in the regulation of microtubule assembly by affecting a number of GSK- $3 \beta$ downstream signaling pathways. In some cases, we measured CRMP-2 phosphorylation levels to quantify GSK-3 $\beta$ activity for demonstrating the association with the microtubule assembly pathway for axonal outgrowth. Our results showed that Dock3 siRNA alone did not suppress CRMP-2 phosphorylation (Fig. 6B), but this can most probably be explained by the compensatory mechanisms exerted by Dock 1,2 and 4 , as they share a common active center (Namekata et al., 2010). Since Dock3 is specifically expressed in the neural tissues (Namekata et al., 2004), we believe that Dock 3 is a promising therapeutic target particularly for conditions such as axonal degeneration. We previously reported that Dock3 forms a complex with activated Fyn and WAVE at the plasma membrane and stimulates BDNF-dependent axonal outgrowth (Namekata et al., 2010). Together, our observations suggest that the BDNFDock3 pathway promotes axonal outgrowth by stimulating dual pathways: the Rac1-mediated actin polymerization pathway and the GSK-3 $\beta$-mediated microtubule assembly pathway (Fig. $8 D$ ). In addition to axon extension, we showed that axonal branching is also influenced by Dock3. The branching pattern of an axon is very important as it defines the spatial distribution of its outputs, specifying the landscape for potential sites of connectivity with postsynaptic partners. Axon branching both establishes general targets of innervation and sculpts on a finer scale the field of innervation within a specific target. The restriction of axon branches to appropriate locales is critical for normal neuronal connectivity and is accomplished by regulating the formation and patterning of branches (Yates et al., 2001; Yamahachi et al., 2009). Thus, it would be interesting to investigate in future whether and how Dock3 may be involved in the formation of neural circuits in vivo.

BDNF-TrkB signaling is important for the formation of inhibitory and excitatory synapses in the CNS, including the hippocampus (Aguado et al., 2003; Luikart et al., 2005). BDNF deficient mice consistently exhibit a marked suppression of longterm potentiation (LTP) (Korte et al., 1995; Patterson et al., 1996). Previous studies have reported that cytoskeletal regulation is also involved in synaptogenesis. For example, activation of GSK-3 $\beta$ and loss of CRMP-1 inhibits LTP with synapseassociated impairments (Zhou and Snider, 2005; Su et al., 2007, Yamashita et al., 2007). In addition, Racl regulates dendritic spine density and shape in rat and mouse pyramidal neurons (Nakayama et al., 2000; Tashiro and Yuste, 2004). Because BDNF 
A

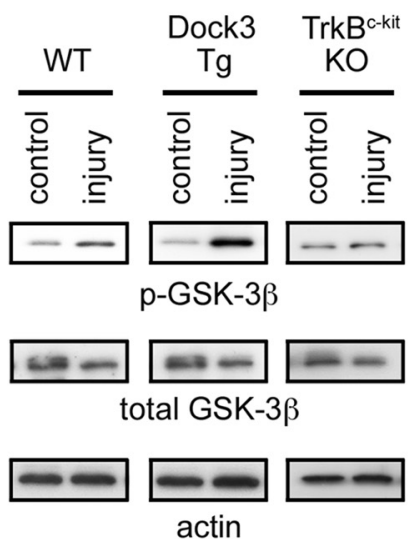

B
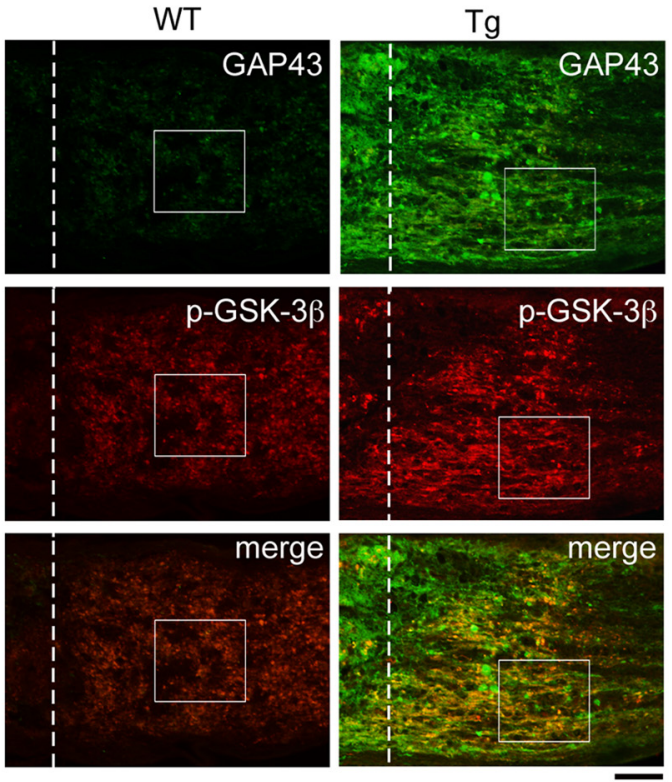

D

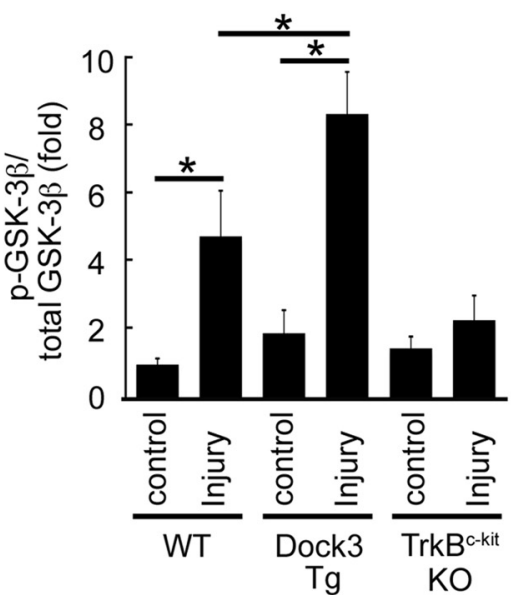

C
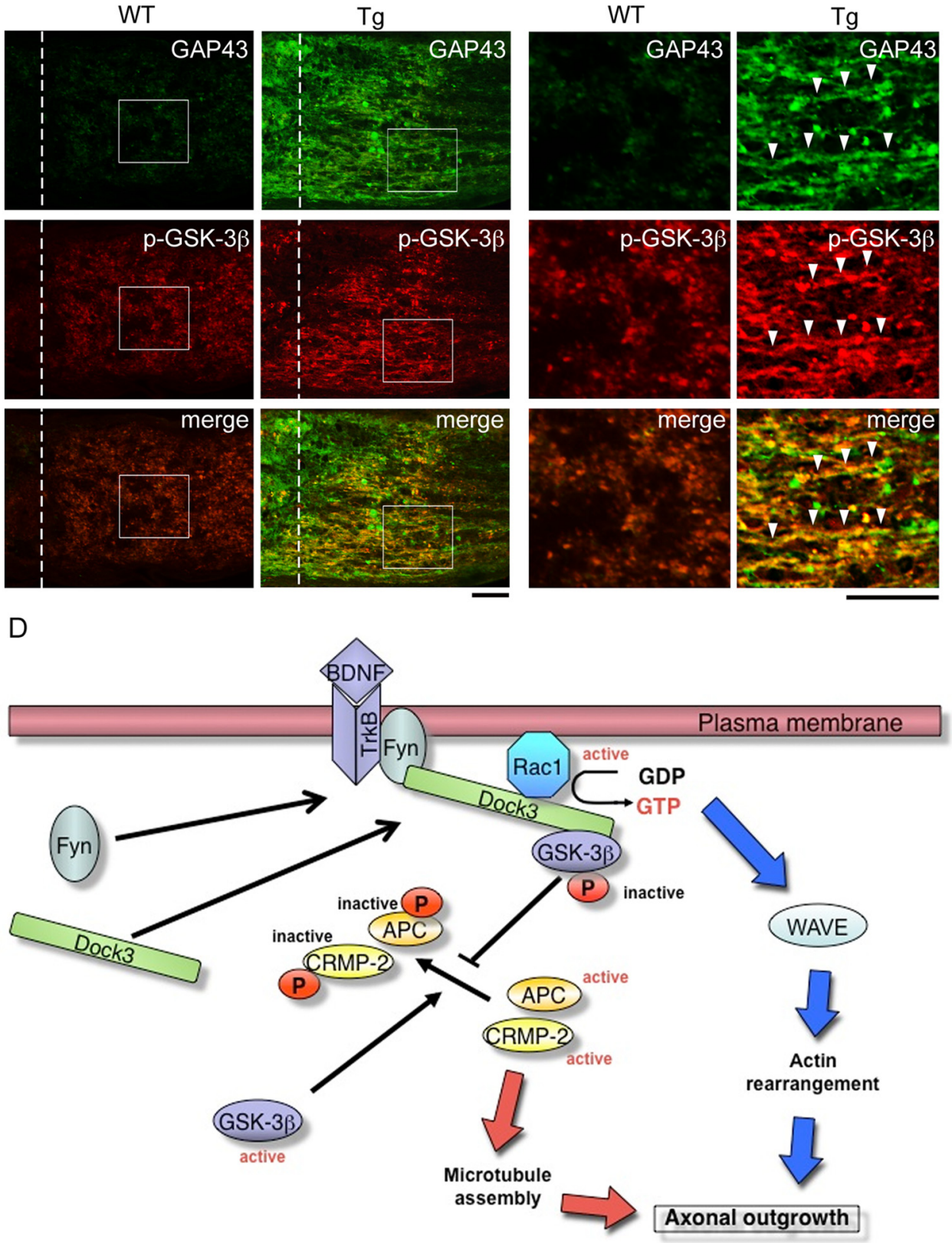
regulates the activity of GSK-3 $\beta$, CRMP-2 and Rac1 at least partly through Dock3 (Fig. 8D), Dock3 may mediate multiple BDNFTrkB functions including the establishment of LTP. In addition to having physiological functions, BDNF has recently been associated with neurological diseases. For example, the Val66Met functional polymorphism in human BDNF is involved in the pathogenesis of attention-deficit hyperactivity disorder (ADHD) (Egan et al., 2003; Friedel et al., 2005; Kent et al., 2005). Interestingly, a pericentric inversion breakpoint in the DOCK3 gene has been described in ADHD patients (de Silva et al., 2003), suggesting a possible link between the BDNF-Dock3 pathway and ADHD. On the other hand, GSK- $3 \beta$ activity has been associated with many psychiatric and neurodegenerative diseases, such as Alzheimer's disease, schizophrenia and autism spectrum disorders, and it has become increasingly apparent that GSK- $3 \beta$ might be a common therapeutic target for different classes of psychiatric drugs (Hur and Zhou, 2010). Intriguingly, Dock3 was initially identified to bind to presenilin 1, a major causative gene of earlyonset familial Alzheimer's disease (Kashiwa et al., 2000; Bertram et al., 2010). In addition, Dock3 expression is significantly reduced in Alzheimer's disease (Kashiwa et al., 2000). Because the intracellular localization of Dock3 modulates GSK-3 $\beta$ activity (Figs. 2C, 3B), the reduced Dock3 expression may be associated with deregulation of GSK- $3 \beta$ activity in Alzheimer's disease.

We also showed that GSK- $3 \beta$ phosphorylation was increased in regenerating axons after optic nerve injury in Dock $3 \mathrm{Tg}$ mice in vivo (Fig. $8 A-C$ ). Based on our findings, we propose that Dock3 promotes GSK- $3 \beta$ recruitment to the plasma membrane, where GSK-3 $\beta$ can be phosphorylated and inactivated in vivo. These observations suggest that both Dock 3 and GSK- $3 \beta$ could be potential targets for regeneration therapy. In addition to stimulating the outgrowth of optic nerve axons, BDNF protects retinal ganglion cells (RGCs) after retinal and optic nerve injury (Harvey et al., 2009; Bessero and Clarke, 2010). Furthermore, GEF activity is involved in cell survival and growth; this is currently primarily studied in the field of cancer research (Lazer and Katzav, 2011). Thus, our findings may be relevant for both RGC protection and optic nerve regeneration. We are currently investigating a role of Dock 3 in the animal models of normal tension glaucoma (Harada et al., 2007, 2010). Further studies are required to fully elucidate the precise roles played by Dock family members during neural development, neurodegeneration and axonal regeneration.

\section{References}

Aguado F, Carmona MA, Pozas E, Aguiló A, Martínez-Guijarro FJ, Alcantara S, Borrell V, Yuste R, Ibañez CF, Soriano E (2003) BDNF regulates spontaneous correlated activity at early developmental stages by increasing synaptogenesis and expression of the $\mathrm{K}^{+} / \mathrm{Cl}^{-}$co-transporter KCC2. Development 130:1267-1280.

\section{$\leftarrow$}

(Figure legend continued.) presented as means \pm SEs for each group from three independent experiments. ${ }^{*} p<0.05 . \boldsymbol{B}, \boldsymbol{C}$, Longitudinal sections through the optic nerve of a WT mouse and a Dock3 Tg mouse stained for GAP43 (green, a marker for regenerating axons) and p-GSK-3 $\beta$ (red). $\boldsymbol{C}$ depicts magnified images of square areas in $\boldsymbol{B}$. The dotted line in $\boldsymbol{B}$ represents the injury site. Arrowheads in C indicate colocalization of GAP43 and p-GSK-3 $\beta$. Scale bars, $50 \mu \mathrm{m}$. D, Proposed role of Dock3 in BDNF-mediated axonal outgrowth. In neurons, BDNF-TrkB signaling induces Fyn phosphorylation and stimulates membrane recruitment of the Dock3/WAVE complex. Dock3 is then able to activate Rac 1 at the plasma membrane, leading to actin rearrangement (blue arrows). In addition, Dock3 binds to GSK-3 $\beta$ and recruits it to the plasma membrane, where GSK-3 $\beta$ is phosphorylated and inactivated. Inactivation of GSK-3 $\beta$ results in an increased amount of the nonphosphorylated active form of CRMP-2 and APC, leading to microtubule assembly (red arrows). Stimulation of actin rearrangement and microtubule assembly both induce axonal outgrowth.
Arimura N, Kaibuchi K (2007) Neuronal polarity: from extracellular signals to intracellular mechanisms. Nat Rev Neurosci 8:194-205.

Beaulieu JM, Gainetdinov RR, Caron MG (2009) Akt/GSK3 signaling in the action of psychotropic drugs. Annu Rev Pharmacol Toxicol 49:327-347.

Bertram L, Lill CM, Tanzi RE (2010) The genetics of Alzheimer disease: back to the future. Neuron 68:270-281.

Bessero AC, Clarke PG (2010) Neuroprotection for optic nerve disorders. Curr Opin Neurol 23:10-15.

Cerione RA, Zheng Y (1996) The Dbl family of oncogenes. Curr Opin Cell Biol 8:216-222.

Cheung ZH, Chin WH, Chen Y, Ng YP, Ip NY (2007) Cdk5 is involved in BDNF-stimulated dendritic growth in hippocampal neurons. PLoS Biol 5:e63.

Conde C, Cáceres A (2009) Microtubule assembly, organization and dynamics in axons and dendrites. Nat Rev Neurosci 10:319-332.

Côté JF, Vuori K (2007) GEF what? Dock180 and related proteins help Rac to polarize cells in new ways. Trends Cell Biol 17:383-393.

de Silva MG, Elliott K, Dahl HH, Fitzpatrick E, Wilcox S, Delatycki M, Williamson R, Efron D, Lynch M, Forrest S (2003) Disruption of a novel member of a sodium/hydrogen exchanger family and DOCK3 is associated with an attention deficit hyperactivity disorder-like phenotype. J Med Genet 40:733-740.

Egan MF, Kojima M, Callicott JH, Goldberg TE, Kolachana BS, Bertolino A, Zaitsev E, Gold B, Goldman D, Dean M, Lu B, Weinberger DR (2003) The BDNF val66met polymorphism affects activity-dependent secretion of BDNF and human memory and hippocampal function. Cell 112:257-269.

Eickholt BJ, Walsh FS, Doherty P (2002) An inactive pool of GSK-3 at the leading edge of growth cones is implicated in Semaphorin 3A signaling. J Cell Biol 157:211-217.

Fischer D, Petkova V, Thanos S, Benowitz LI (2004) Switching mature retinal ganglion cells to a robust growth state in vivo: gene expression and synergy with RhoA inactivation. J Neurosci 24:8726-8740.

Friedel S, Horro FF, Wermter AK, Geller F, Dempfle A, Reichwald K, Smidt J, Brönner G, Konrad K, Herpertz-Dahlmann B, Warnke A, Hemminger U, Linder M, Kiefl H, Goldschmidt HP, Siegfried W, Remschmidt H, Hinney A, Hebebrand J (2005) Mutation screen of the brain derived neurotrophic factor gene (BDNF): identification of several genetic variants and association studies in patients with obesity, eating disorders, and attention-deficit/hyperactivity disorder. Am J Med Genet B Neuropsychiatr Genet 132B:96-99.

Harada C, Namekata K, Guo X, Yoshida H, Mitamura Y, Matsumoto Y, Tanaka K, Ichijo H, Harada T (2010) ASK1 deficiency attenuates neural cell death in GLAST-deficient mice, a model of normal tension glaucoma. Cell Death Differ 17:1751-1759.

Harada C, Guo X, Namekata K, Kimura A, Nakamura K, Tanaka K, Parada LF, Harada T (2011) Glia- and neuron-specific functions of TrkB signalling during retinal degeneration and regeneration. Nat Commun 2:189.

Harada T, Harada C, Nakamura K, Quah HM, Okumura A, Namekata K, Saeki T, Aihara M, Yoshida H, Mitani A, Tanaka K (2007) The potential role of glutamate transporters in the pathogenesis of normal tension glaucoma. J Clin Invest 117:1763-1770.

Harvey AR, Hellström M, Rodger J (2009) Gene therapy and transplantation in the retinofugal pathway. Prog Brain Res 175:151-161.

Huang X, Guo B (2006) Adenomatous polyposis coli determines sensitivity to histone deacetylase inhibitor-induced apoptosis in colon cancer cells. Cancer Res 66:9245-9251.

Hur EM, Zhou FQ (2010) GSK3 signalling in neural development. Nat Rev Neurosci 11:539-551.

Inagaki N, Chihara K, Arimura N, Ménager C, Kawano Y, Matsuo N, Nishimura T, Amano M, Kaibuchi K (2001) CRMP-2 induces axons in cultured hippocampal neurons. Nat Neurosci 4:781-782.

Kashiwa A, Yoshida H, Lee S, Paladino T, Liu Y, Chen Q, Dargusch R, Schubert $\mathrm{D}$, Kimura $\mathrm{H}$ (2000) Isolation and characterization of novel presenilin binding protein. J Neurochem 75:109-116.

Kent L, Green E, Hawi Z, Kirley A, Dudbridge F, Lowe N, Raybould R, Langley K, Bray N, Fitzgerald M, Owen MJ, O’Donovan MC, Gill M, Thapar A, Craddock N (2005) Association of the paternally transmitted copy of common Valine allele of the Val66Met polymorphism of the brain-derived neurotrophic factor (BDNF) gene with susceptibility to ADHD. Mol Psychiatry 10:939-943. 
Kim WY, Zhou FQ, Zhou J, Yokota Y, Wang YM, Yoshimura T, Kaibuchi K, Woodgett JR, Anton ES, Snider WD (2006) Essential roles for GSK-3s and GSK-3-primed substrates in neurotrophin-induced and hippocampal axon growth. Neuron 52:981-996.

Koester MP, Müller O, Pollerberg GE (2007) Adenomatous polyposis coli is differentially distributed in growth cones and modulates their steering. J Neurosci 27:12590-12600.

Korte M, Carroll P, Wolf E, Brem G, Thoenen H, Bonhoeffer T (1995) Hippocampal long-term potentiation is impaired in mice lacking brainderived neurotrophic factor. Proc Natl Acad Sci U S A 92:8856-8860.

Kumar P, Lyle KS, Gierke S, Matov A, Danuser G, Wittmann T (2009) GSK3beta phosphorylation modulates CLASP-microtubule association and lamella microtubule attachment. J Cell Biol 184:895-908.

Lazer G, Katzav S (2011) Guanine nucleotide exchange factors for RhoGTPases: Good therapeutic targets for cancer therapy? Cell Signal 23:969-979.

Lemmon MA, Ferguson KM (2000) Signal-dependent membrane targeting by pleckstrin homology (PH) domains. Biochem J 350:1-18.

Luikart BW, Nef S, Virmani T, Lush ME, Liu Y, Kavalali ET, Parada LF (2005) TrkB has a cell-autonomous role in the establishment of hippocampal Schaffer collateral synapses. J Neurosci 25:3774-3786.

Meller N, Merlot S, Guda C (2005) CZH proteins: a new family of RhoGEFs. J Cell Sci 118:4937-4946.

Nakamura K, Namekata K, Harada C, Harada T (2007) Intracellular sortilin expression pattern regulates proNGF-induced naturally occurring cell death during development. Cell Death Differ 14:1552-1554.

Nakayama AY, Harms MB, Luo L (2000) Small GTPases Rac and Rho in the maintenance of dendritic spines and branches in hippocampal pyramidal neurons. J Neurosci 20:5329-5338.

Namekata K, Enokido Y, Iwasawa K, Kimura H (2004) MOCA induces membrane spreading by activating Rac1. J Biol Chem 279:14331-14337.

Namekata K, Harada C, Kohyama K, Matsumoto Y, Harada T (2008) Interleukin-1 stimulates glutamate uptake in glial cells by accelerating membrane trafficking of $\mathrm{Na}^{+} / \mathrm{K}^{+}$-ATPase via actin depolymerization. Mol Cell Biol 28:3273-3280.

Namekata K, Harada C, Taya C, Guo X, Kimura H, Parada LF, Harada T (2010) Dock3 induces axonal outgrowth by stimulating membrane recruitment of the WAVE complex. Proc Natl Acad Sci U S A 107:7586-7591.

Patterson SL, Abel T, Deuel TA, Martin KC, Rose JC, Kandel ER (1996) Recombinant BDNF rescues deficits in basal synaptic transmission and hippocampal LTP in BDNF knockout mice. Neuron 16:1137-1145.
Purro SA, Ciani L, Hoyos-Flight M, Stamatakou E, Siomou E, Salinas PC (2008) Wnt regulates axon behavior through changes in microtubule growth directionality: a new role for adenomatous polyposis coli. J Neurosci 28:8644-8654.

Schmidt A, Hall A (2002) Guanine nucleotide exchange factors for Rho GTPases: turning on the switch. Genes Dev 16:1587-1609.

Su KY, Chien WL, Fu WM, Yu IS, Huang HP, Huang PH, Lin SR, Shih JY, Lin YL, Hsueh YP, Yang PC, Lin SW (2007) Mice deficient in collapsin response mediator protein-1 exhibit impaired long-term potentiation and impaired spatial learning and memory. J Neurosci 27:2513-2524.

Takenawa T, Suetsugu S (2007) The WASP-WAVE protein network: connecting the membrane to the cytoskeleton. Nat Rev Mol Cell Biol 8:37-48.

Tashiro A, Yuste R (2004) Regulation of dendritic spine motility and stability by Racl and Rho kinase: evidence for two forms of spine motility. Mol Cell Neurosci 26:429-440.

Yamahachi H, Marik SA, McManus JN, Denk W, Gilbert CD (2009) Rapid axonal sprouting and pruning accompany functional reorganization in primary visual cortex. Neuron 64:719-729.

Yamashita N, Morita A, Uchida Y, Nakamura F, Usui H, Ohshima T, Taniguchi M, Honnorat J, Thomasset N, Takei K, Takahashi T, Kolattukudy P, Goshima Y (2007) Regulation of spine development by semaphorin3A through cyclin-dependent kinase 5 phosphorylation of collapsin response mediator protein 1. J Neurosci 27:12546-12554.

Yates PA, Roskies AL, McLaughlin T, O'Leary DD (2001) Topographicspecific axon branching controlled by ephrin-As is the critical event in retinotectal map development. J Neurosci 21:8548-8563.

Yoshimura T, Kawano Y, Arimura N, Kawabata S, Kikuchi A, Kaibuchi K (2005) GSK-3 $\beta$ regulates phosphorylation of CRMP-2 and neuronal polarity. Cell 120:137-149.

Zhao Z, Wang Z, Gu Y, Feil R, Hofmann F, Ma L (2009) Regulate axon branching by the cyclic GMP pathway via inhibition of glycogen synthase kinase 3 in dorsal root ganglion sensory neurons. J Neurosci 29:1350-1360.

Zhou FQ, Snider WD (2005) Cell biology. GSK-3 $\beta$ and microtubule assembly in axons. Science 308:211-214.

Zhou FQ, Zhou J, Dedhar S, Wu YH, Snider WD (2004) NGF-induced axon growth is mediated by localized inactivation of GSK-3 $\beta$ and functions of the microtubule plus end binding protein APC. Neuron 42:897-912. 